\title{
The effects of naloxone on human breast cancer progression: in vitro and in vivo studies on MDA.MB23 I cells
}

This article was published in the following Dove Press journal: OncoTargets and Therapy

\author{
Sabrina Bimonte ${ }^{1, *}$ \\ Antonio Barbieri ${ }^{2, *}$ \\ Marco Cascella ${ }^{1, *}$ \\ Domenica $\mathrm{Rea}^{2, *}$ \\ Giuseppe Palma ${ }^{2}$ \\ Vitale Del Vecchio \\ Cira Antonietta Forte' \\ Francesco Del Prato' \\ Claudio Arra' \\ Arturo Cuomo² \\ 'Division of Anesthesia and Pain \\ Medicine, Istituto Nazionale Tumori - \\ IRCCS - "Fondazione G. Pascale", \\ ${ }^{2}$ Animal Facility Unit, Department of \\ Research, National Cancer Institute \\ "G. Pascale", Naples, Italy \\ *These authors contributed equally \\ to this work
}

Correspondence: Sabrina Bimonte Division of Anesthesia and Pain Medicine, Istituto Nazionale Tumori - IRCCS "Fondazione G. Pascale", Via Mariano Semmola, 80I3I Naples, Italy Email s.bimonte@istitutotumori.na.it
Background: Naloxone is viewed as a specific competitive opioid antagonist acting at the level of opioid receptors $(\mu, \delta$, and $\kappa)$ with blended agonist-adversary or agonist action. The role of naloxone in tumor cell growth has been poorly studied in human cancer cell lines.

Materials and methods: In the present study, we report findings from in vitro and in vivo experiments performed to evaluate the effects of naloxone on human breast cancer cell growth and progression. In vitro assays were conducted on estrogen receptor-negative human breast carcinoma cells, MDA.MB231, treated with naloxone at different concentrations (10-100 $\mu \mathrm{M})$. In vivo experiments were performed on a mouse model of human triple-negative breast cancer generated by using MDA.MB231 injected subcutaneously in mice. Naloxone was daily intraperitoneally injected in mice at $0.357 \mathrm{mg} / \mathrm{kg}$ for 2 weeks and at $0.714 \mathrm{mg} / \mathrm{kg}$ for the next 2 weeks. Microvessels formation was detected by fluorescein isothiocyanate-dextran $(100 \mu \mathrm{L})$ injected into the tail vein of mice and confirmed by immunohistochemistry with CD31 on mice tumor sections.

Results: In vitro tests showed that the cell proliferation of MDA.MB231 was inhibited by naloxone in a dose-dependent manner, whereas the cell death was increased. In vivo studies demonstrated that tumors of mice treated with naloxone were significantly smaller than those observed in the control groups, as long as naloxone was administered. Finally, naloxone was not able to impair the microvessel formation in tumors of treated mice.

Conclusion: Our data showed, for the first time, that naloxone reduced breast cancer progression without affecting angiogenesis.

Keywords: naloxone, breast cancer, proliferation, microvessel formation, angiogenesis

\section{Introduction}

Naloxone is a specific, competitive opioid antagonist acting at opioid receptors $(\mu, \delta$, and $\kappa)$ with an agonist or mixed agonist-antagonist activity. It has been reported that naloxone has multiple activities in numerous processes. It acts as an immunoadjuvant in cancer immunotherapy, ${ }^{1-3}$ and it regulates, in conjunction with other opioids, the apoptosis $^{4-6}$ in human cancer cells. ${ }^{7,8}$ In addition, it has been proved that naloxone can influence the proliferation and neurogenesis in cultured rat adult hippocampal progenitors. ${ }^{9}$ Moreover, naloxone is known as the principal antagonist of morphine, an opiate-based drug largely used to relieve pains of cancer patients, ${ }^{10-13}$ through a complex action on receptors localized in the brain. ${ }^{14,15}$

To date, several in vitro and in vivo studies, performed on various human cancer cell lines ${ }^{8,16-20}$ or animal models of cancer, ${ }^{21-26}$ showed that morphine has a role in the regulation of cancer cell growth and progression with contrasting results depending on the different doses of the drug used in the experiments. ${ }^{27} \mathrm{We}$ and others previously 
demonstrated that morphine acts as a breast cancer-promoting drug at clinically relevant doses. ${ }^{26,28}$ Additionally, we reported an enhancement of angiogenesis, ${ }^{29,30}$ a crucial process connected with cancer, in breast tumors induced by morphine.

A promoting role in chemoresistance of breast cancer cells induced by morphine by enhancing properties of cancer stem cells has also been reported. ${ }^{31}$ On the opposite facet, fewer studies have been conducted on the possible roles of naloxone in tumor cancer progression. Kikuchi et al showed that naloxone was able to inhibit human ovarian cancer cell growth, in experimental in vitro and in vivo studies. ${ }^{32}$ Similar results were also reported for MCF-7 breast cancer cells. ${ }^{33,34}$

Here we reported, for the first time, findings on the role of naloxone in the regulation of the estrogen receptor (ER)negative human breast carcinoma cells, MDA.MB231 cell growth, and microvessel formation in triple-negative breast cancer (TNBC). Our data showed that naloxone reduced breast cancer progression without significant effect on tumor angiogenesis.

\section{Materials and methods \\ Materials}

Naloxone hydrochloride was purchased from Molteni. Different doses of naloxone $(1,10$, and $100 \mu \mathrm{M})$ were used for in vitro experiments on MDA.MB231 cells. The antibody against CD31 was obtained from DAKO (Santa Cruz, CA, USA). The anti-p53 antibody was provided by Imgenex (San Diego, CA, USA). 3,3-diaminobenzidine horseradish peroxidase (HRP) substrate was obtained from Vector Laboratories (USA). Antibiotics (penicillin and streptomycin), Dulbecco's Modified Eagle's Medium (DMEM), and fetal bovine serum (FBS) were purchased from Invitrogen (Grand Island, NY, USA). Tris, glycine, $\mathrm{NaCl}$, sodium dodecyl sulfate (SDS), and bovine serum albumin were obtained from Sigma Chemical (St Louis, MO, USA).

\section{Cell culture}

The human ER-negative breast cancer cell line MDA. MB231 was obtained from American Type Culture Collection (ATCC ${ }^{\circledR}$ HTB-26 ${ }^{\text {TM }}$ Manassas, VA, USA). Cells were cultured in DMEM (Hyclone, UT, USA) supplemented with $10 \%$ heat-inactivated FBS, antibiotics (penicillin $100 \mathrm{U} / \mathrm{mL}$; streptomycin $100 \mathrm{U} / \mathrm{mL})$, and L-glutamine $(2 \mathrm{mM})$ in $5 \%$ of $\mathrm{CO}_{2}$ and humidified atmosphere at $37^{\circ} \mathrm{C}$.

\section{Scratch wound-healing assay}

The scratch wound-healing assay was used to evaluate the migration of MDA.MB231 cells. Cells were seeded into sixmultiwell plates and cultured in DMEM supplemented with
$1 \%$ FBS. At the time of confluence, cells were incubated in the absence or presence of naloxone $(1,10$, and $100 \mu \mathrm{M})$ for $48 \mathrm{~h}$. Then, uniform wounds were scraped with sterile $200 \mu \mathrm{L}$ pipette tips, and the floating cells were removed by washing with phosphate-buffered saline (PBS). Cell invasion on the slit of the confluent well was assessed at 0,24 , and $48 \mathrm{~h}$, in each condition, by light microscopy. To measure wound areas, we used ImageJ software and analyzed the degree of wound closure at $48 \mathrm{~h}$ based on the area of control condition as 1.00 .

\section{3-[4,5-dimethylthiazol-2-yl]-2, 5-diphenyltetrazolium bromide (MTT) assay}

The effect of the drug on cell proliferation was determined by using TACS (MTT) cell proliferation assay (Trevigen, Gaithersburg). The cells (2,000 per well) were incubated with or without naloxone in triplicate in a 96-well plate and then incubated for 2,4 , and 6 days at $37^{\circ} \mathrm{C}$. An MTT solution was added to each well and incubated for $2 \mathrm{~h}$ at $37^{\circ} \mathrm{C}$. An extraction buffer (20\% SDS and 50\% dimethylformamide) was added, and the cells were incubated overnight at $37^{\circ} \mathrm{C}$. The absorbance of the cell suspension was measured at $570 \mathrm{~nm}$ using a microplate reader (DAS Technologies, Chantilly, VA, USA).

\section{In vitro apoptosis assay by flow cytometry} Cells were washed and suspended in $0.5 \mathrm{~mL}$ of PBS, fluorescein isothiocyanate (FITC)-Annexin V, and propidium iodide (PI). Cells were incubated for $30 \mathrm{~min}$ on ice in the dark and analyzed by flow cytometry (FACScan, Becton Dickinson, Franklin Lakes, NJ, USA) by measurements of fluorescence emission at 530 and $575 \mathrm{~nm}$. The apoptotic cells were stained with FITC-Annexin V, while necrotic cells were stained with PI. The apoptotic fraction was obtained by dividing the number of apoptotic cells by the total number of cells (minimum of 104 cells). Data were analyzed using Cell Quest software (Becton Dickinson). All data were reproduced by three independent experiments.

\section{Western blot analysis}

Western blotting analysis was performed according to the protocol previously described. ${ }^{28,39} \beta$-actin was used as a loading control. Densitometry was used to measure p53's protein levels by using ImageJ $1.37 \mathrm{v}$ software.

\section{Mice}

A total of 16 eight-week-old female nude mice were purchased from Harlan, San Pietro al Natisone, Italy. Mice were housed five per cage in the standard mice Plexiglas cages 
and maintained on a $12 \mathrm{~h}$ light: $12 \mathrm{~h}$ dark cycle (lights on at $7.00 \mathrm{am})$ in a temperature-controlled room $\left({ }^{\circ} \mathrm{C}\right)$, with food and water ad libitum at all times.

\section{Xenograft mouse model of breast cancer}

Xenograft mouse model of breast cancer was generated by using MDA.MB231 breast cancer cells $\left(2.5 \times 10^{6}\right)$ injected subcutaneously in each mouse as we previously described. ${ }^{28}$ The mice were anesthetized with Zoletil 100 (Virbac) solution, injected intraperitoneally according to their weight, as previously described. ${ }^{35}$ After randomization, mice (eight mice/group) were divided into two groups on the basis of different treatments: 1) normal saline (vehicle); 2) naloxone hydrochloride at $0.357 \mathrm{mg} / \mathrm{kg}$ daily for 2 weeks and then $0.714 \mathrm{mg} / \mathrm{kg}$ for the next 2 weeks. Tumor volumes were measured once a week by using a digital caliper, and volumes were calculated by using the following formula: volume $\left(\mathrm{mm}^{3}\right)=$ length $\times$ width $\times$ width $/ 2$. Normally distributed data were represented as mean \pm standard error of the mean. Paired $t$-test one-tailed analysis was used to examine the significance of differences among two groups (Graph Pad Prism 5.0).

FITC-dextran $(100 \mu \mathrm{L})$ was injected into the tail vein of mice to detect microvessels formation by using Macrofluo microscope as we previously described. ${ }^{28}$

The study was approved by the Italian Animal Ethics Committee of Istituto Nazionale dei Tumori Fondazione G. Pascale of Naples. All experiments were performed by also following the European Directive 63/2010/UE and the Italian Law (DL 116/92, authorized by Minister of Health, Italy; Prot.N. 905/2013). This study was carried out in accordance with the recommendations that cover all scientific procedures involving the use of live animals.

\section{Immunohistochemistry (IHC) staining}

IHC staining was performed by Dr Giosuè Scognamiglio of Department of Pathology of IRCSS Istituto Nazionale dei Tumori Fondazione G. Pascale. Serial sections of tumors from controls and treated mice were embedded in paraffin and fixed with paraformaldehyde. After being washed in PBS, the slides were blocked with protein block solution (DakoCytomation) for $20 \mathrm{~min}$ and then incubated overnight with anti-CD31 antibodies (mouse monoclonal, clone JC70A, DAKO 1:10 dilution). After the incubation, the slides were washed and then incubated with biotinylated link universal antiserum followed by HRP-streptavidin conjugate $(\mathrm{LSAB}+\mathrm{kit})$. The slides were rinsed, and the color was developed using 3,3'-diaminobenzidine hydrochloride as a chromogen. Finally, sections were rinsed in distilled water, counterstained with hematoxylin, and mounted with DPX mounting medium for evaluation. Pictures were captured with a Photometrics CoolSNAP CF color camera (Nikon, Lewisville, TX, USA) and analyzed with Image-Pro Plus software (Version 6.0, Media Cybernetics, Bethesda, MD, USA). Digital images of at least three different areas of each section (from three different sections per tumor) were examined. Vascular endothelial cells that stained positively for CD31 were counted. Microvessel density (MVD) was counted according to protocols previously described. ${ }^{36-38}$

\section{Statistical analyses}

Statistical analyses were performed with SPSS version 18.0 (SPSS, Chicago, IL, USA). All experiments mentioned above were repeated three times. Data were presented as mean \pm SD. Two-tailed $t$-test and $\chi^{2}$ test were used for comparisons between the different groups. $P<0.05$ was considered statistically significant.

\section{Results}

Naloxone inhibits the proliferation and enhances the apoptosis of MDA.MB23I cells

To understand the effects of naloxone on the proliferation of MDA.MB231 cells, we performed in vitro studies by qualitative and quantitative tests. Scratch wound-healing assay demonstrated that naloxone inhibited the migration of MDA.MB231 cells at $48 \mathrm{~h}$ in a dose-dependent manner, with the major effect observed at $100 \mu \mathrm{M}$ (Figure 1A-D). MTT assay and flow cytometry analysis confirmed these data (Figure 2A and B). To assess if naloxone influenced the apoptosis in MDA.MB231 cells, we performed western blotting analysis of $\mathrm{p} 53$ expression on cell lysate extracted from MBA.MB231 cells not treated and treated with naloxone (Figure 3). Taken together, our data showed that naloxone was able to promote apoptosis and to inhibit proliferation of breast cancer cells in a dose-dependent manner.

\section{Naloxone inhibited tumor growth without affecting angiogenesis in mouse model of triple-negative breast cancer}

In vivo experiments were conducted on a xenograft mouse model of TNBC, generated by subcutaneous injection of MDA.MB231 cells as described in the methods explained earlier, to assess the antitumor effects of naloxone. Naloxone was able to retard tumor growth in the treated mice with respect to controls mainly on day 35 after the beginning of treatment (Figure 4). Measurements of mice's body weights did not show differences between the two groups of animals, 

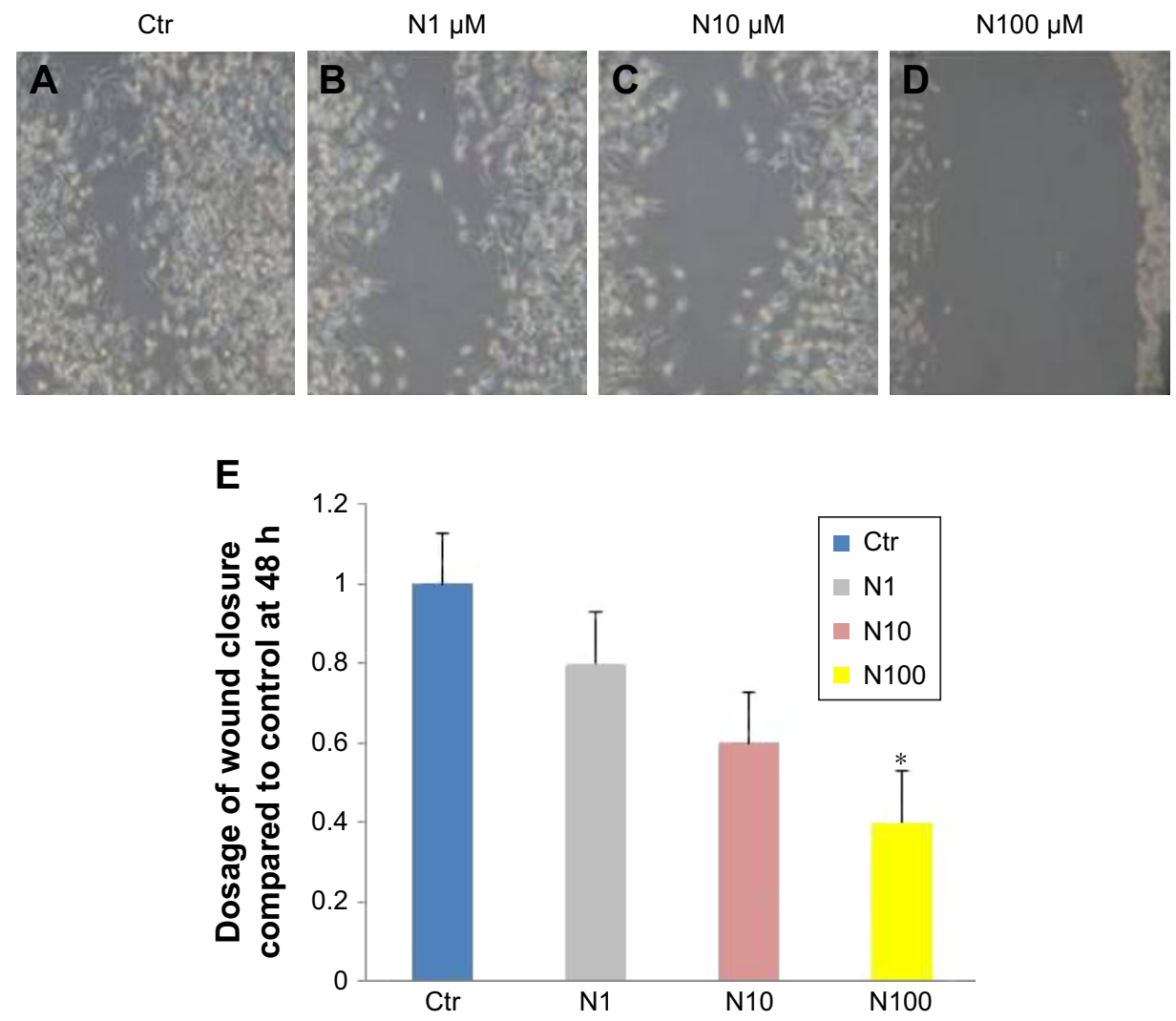

Figure I Naloxone inhibits the migration of MDA.MB23I cells.

Notes: MDA.MB23 I cells were incubated in medium alone as $\mathrm{Ctr}(\mathbf{A}),(\mathbf{B})$ I $\mu$ M naloxone (NI), (C) I0 $\mu$ M naloxone (NI0), and (D) I00 $\mu$ M naloxone (NI00). Cell migration rates were quantitatively assessed by counting the number of cells in the denuded area at 0,24 , and $48 \mathrm{~h}$ after wound induction. At $48 \mathrm{~h}$ after wound induction, there were clearly fewer cells in the denuded area of naloxone-treated cells than untreated cells. (E) Wound closure was analyzed at $48 \mathrm{~h}$ after wounding. Values were mean $\pm \mathrm{SE}$ for three independent experiments. $* P<0.05$.

Abbreviation: Ctr, control.

thus suggesting minimal toxicity induced by naloxone (data not shown).

As angiogenesis plays significant roles in cancer appearance and progression, we hypothesized that breast tumor growth was inhibited by naloxone via impairment of angiogenesis. For this purpose, we tested the effect of naloxone on the intratumoral MVD by injection of FITCdextran into the tail vein of mice. Our results showed that microvessel formation was not inhibited by naloxone in tumors from naloxone-treated mice with respect to controls (Figure 5A and B). An IHC analysis with CD31 and counts for MVD (differences were not statistically significant)
A

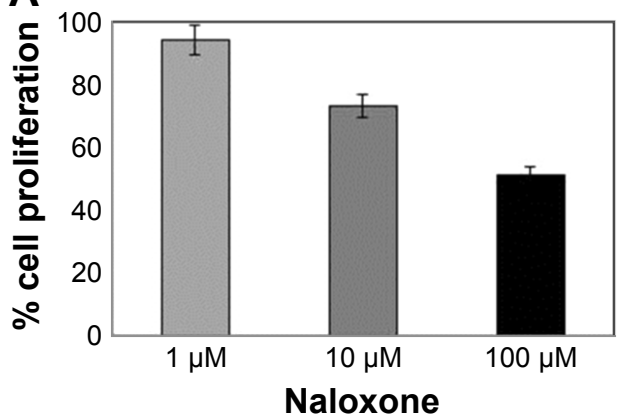

B

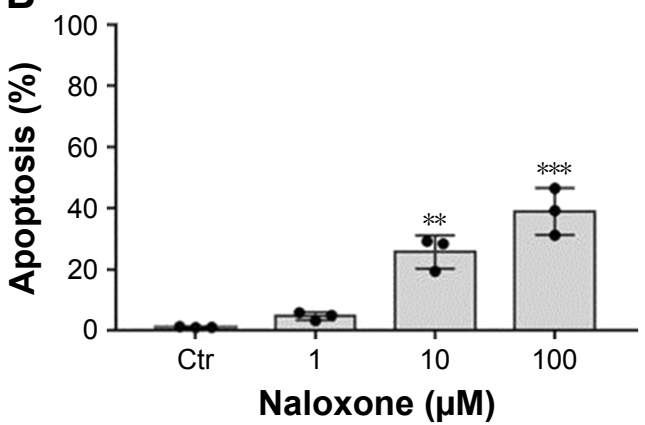

Figure 2 Naloxone inhibits proliferation and increases apoptosis in MDA.MB23 I cells in a dose-dependent manner.

Notes: (A) 3-[4,5-dimethylthiazol-2-yl]-2,5-diphenyltetrazolium bromide assay results show an enhancement of proliferation in breast cancer cells treated with naloxone with respect to Ctr cells. Data are representative of three independent experiments. (B) In vitro apoptosis assay by flow cytometry showed the effect of the naloxone on MDA-MB.23I cell's apoptosis. The treatments with naloxone at $100 \mu \mathrm{M}$ enhanced the apoptosis level on the breast cancer cell line. Data presented as mean \pm SD. Significance: $* * P<0.01$ and $* * * P<0.001$ by analysis of variance, compared with $\mathrm{Ctr}$.

Abbreviation: Ctr, control. 
A
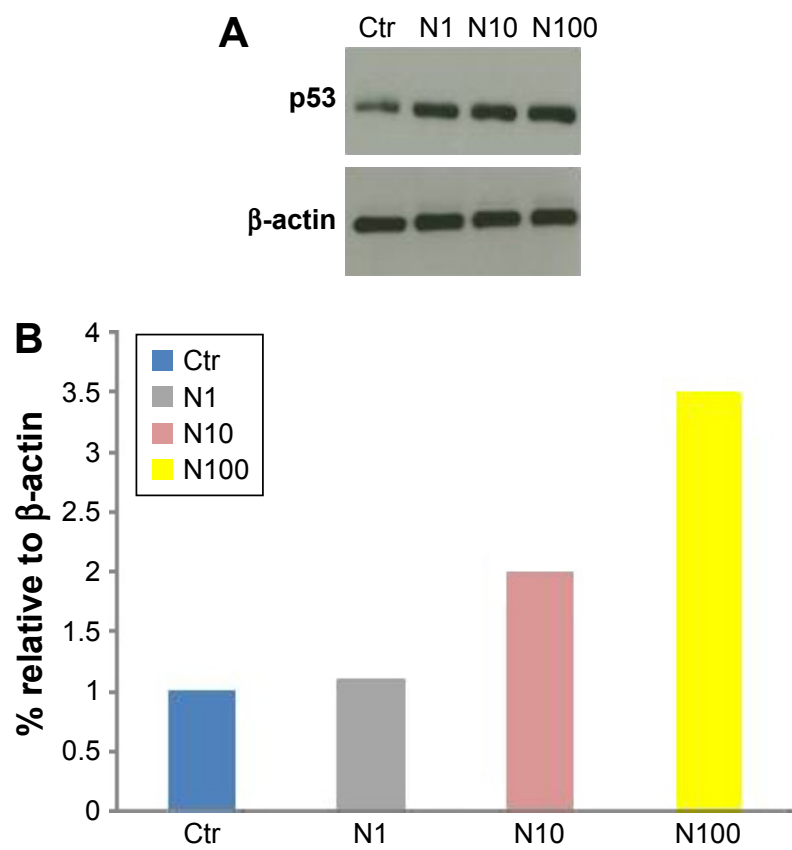

Figure 3 Naloxone enhances apoptosis in MDA.MB23। cells.

Notes: (A) Western blot analysis shows that naloxone enhanced $p 53$ expression in MDA.MB23I cells treated (NI $\mu \mathrm{M}, \mathrm{NIO} \mu \mathrm{M}, \mathrm{NI00 \mu M})$ with respect to Ctr in a dose-dependent manner. $\beta$-actin was used as a loading Ctr. (B) Graphical representation of the $p 53$ levels relative to $\beta$-actin in $C$ tr, and cells treated with $\mathrm{NI}, \mathrm{NIO}$, and NIOO.

Abbreviation: Ctr, control.

in tumor tissues from control and naloxone-treated mice confirmed these data (Figure 6A-C). Taken together, these results suggest that naloxone inhibits breast tumor growth without affecting angiogenesis.

\section{Discussion}

The role of naloxone in the regulation of tumor cell growth has not been extensively studied. An inhibitory role of naloxone

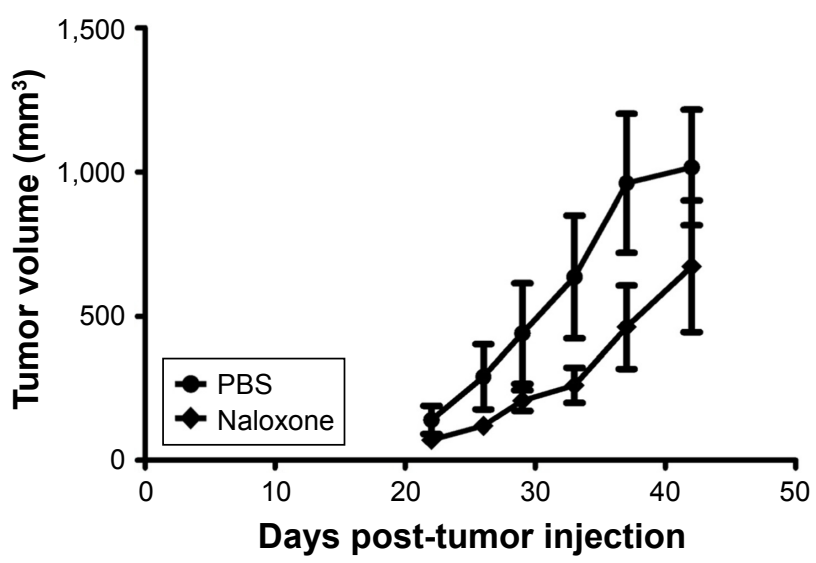

Figure 4 Naloxone inhibits the tumor growth in a triple-negative breast cancer mouse model.

Notes: Breast tumor growth in mice treated with vehicle $(\bullet)$ and naloxone $(\bullet)$. Tumor volumes decreased after 28 days of naloxone treatment until 40 days as compared with controls with significant evidence at 35 days post-treatment. Each point represents the mean of five separate experiments.

Abbreviation: PBS, phosphate-buffered saline.
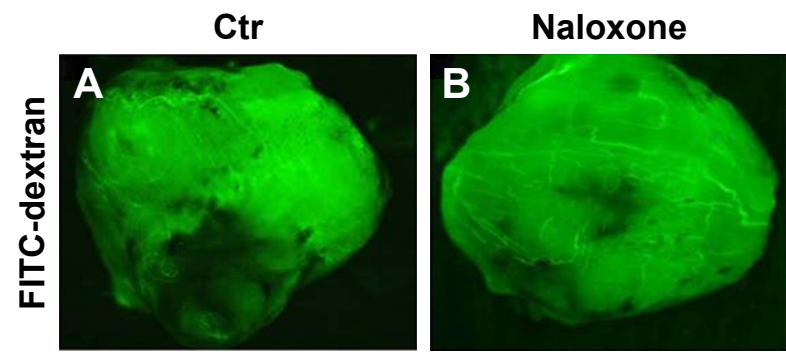

Figure $\mathbf{5}$ Naloxone does not influence microvessel formation in breast tumors. Note: (A, B) Measurements of fluorescence per second depicting microvessel formation in breast tumors (FITC-dextran) using MacroFluo images show that naloxone is not able to impair the angiogenesis in the tumors of naloxone-treated mice (B) with respect to controls (A).

Abbreviations: Ctr, control; FITC, fluorescein isothiocyanate.

in human ovarian cancer cell growth was reported by Kikuchi et al by in vitro and in vivo experiments. ${ }^{32}$ Specifically, the authors showed that naloxone impaired the growth of cells derived from human serous cystadenocarcinoma of the ovary, named KF, in the concentration range of 30-120 $\mu \mathrm{M}$ through inhibition of protein synthesis in KF cells. These results were also confirmed in a mouse model of ovarian cancer. Similar data were also reported for MCF-7 breast cancer cells. ${ }^{33,34}$ For these reasons, in order to elucidate the role of naloxone in the regulation of tumor growth we performed in vitro and in vivo studies on the MDA.MB231 breast cancer cells. It is interesting to underline that MDA.MB231 cells selected for these experiments are basal-like TNBC cells. Thus, they do not express the ER, progesterone receptor, or human epidermal growth factor receptor type 2 (HER2). Conventional endocrine therapy and HER2 targeted therapy on patients with TNBC fail because these patients lack both hormone receptors and do not express HER2. So, TBNC mouse model represents an optimal model to test the roles of the drugs in the regulation of cancer cell growth and angiogenesis. Our data showed that naloxone is able to inhibit tumor breast growth in vitro and in vivo, probably through a mechanism mediated by $\mathrm{p} 53$. These data are in accordance with the previous in vitro and in vivo reports from Gupta et al, ${ }^{34}$ in MCF-7 cells. The authors demonstrated that as morphine enhanced angiogenesis and breast tumor growth by the regulation of cell-cycle pathway at high doses, naloxone reduced breast tumor growth without affecting angiogenesis. On the contrary, Ishikawa et $\mathrm{a}^{26}$ in a study conducted on a mouse model of sarcoma and leukemia showed that naloxone was not able to inhibit tumor growth, but its effects were limited to antagonize the immunosuppressive action of morphine. These different data are probably due to several factors, such as different dosages, in vitro and in vivo system used, and the undiscovered molecular mechanism underlying the effect of naloxone on tumor growth. Thus, more studies are needed 


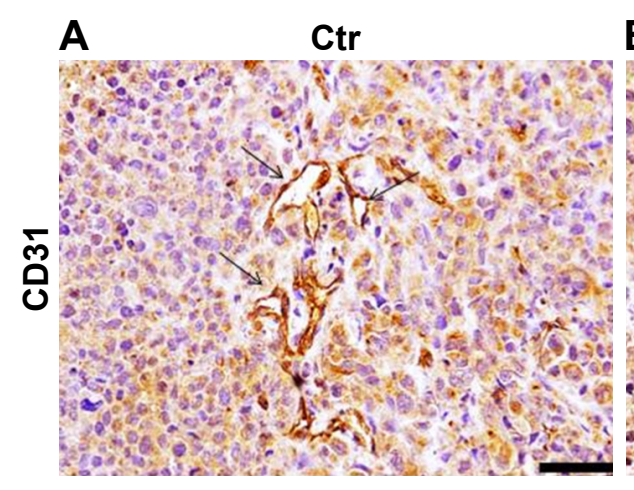

B Naloxone

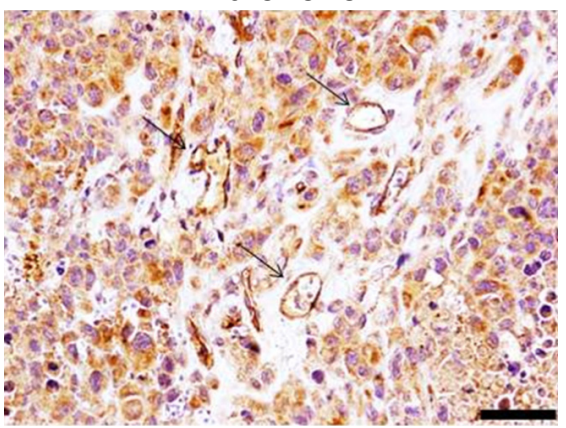

C

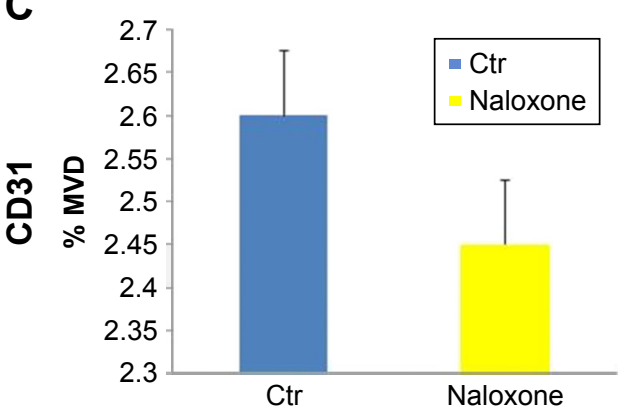

Figure 6 Effects of naloxone on MVD of the breast tumors.

Notes: (A, B) IHC analysis for CD3I showed no reduction of CD3I expression in naloxone-treated mice (B), compared to Ctr. (A) Arrows indicate CD3 I-positive cells. Magnifications 40X. Scale bar: $140 \mu \mathrm{m}$. (C) Quantification of IHC assay was represented as a percentage of CD3I-positive cells (MVD). Data shown were averages with SD (error bars) from eight individual mice in each group ( $P>0.05$, versus controls).

Abbreviations: Ctr, control; IHC, immunohistochemistry; MVD, microvessel density.

to clarify this issue. Interesting results will be obtained by a study, ongoing in our laboratory, on the effects of combination of naloxone with morphine on breast tumor growth and angiogenesis in a mouse model of TNBC.

The results obtained from these experiments allow us to shed a light on the role of naloxone in the regulation of breast cancer development and progression, by antagonizing the effects of morphine, and to develop novel naloxone-based therapeutic compounds, for breast cancer therapy.

\section{Conclusion}

Here we reported, for the first time, findings on the role of naloxone in the regulation of the ER-negative human breast carcinoma cells, and MDA.MB231 cell growth in TNBC. Our data showed that naloxone reduced breast cancer progression without affecting angiogenesis. Future studies will be necessary to dissect the mechanisms underlying the roles of naloxone in cancer growth and progression.

\section{Acknowledgments}

We are grateful to Dr Alessandra Trocino, Mrs Mariacristina Romano, and Mr Massimiliano Spinelli from the National Cancer Institute of Naples for providing excellent bibliographic service and assistance. This work was supported by the current research program of National Institute of Tumors, IRCCS "Foundation G. Pascale," Naples (Italy). We are grateful to Dr Antonio Luciano and Dr Michela Falco from the National Cancer Institute of Naples for providing technical assistance in experiments with animals. We are grateful to Dr Gennaro Russo and Dr Gennaro Esposito for providing assistance in the formulations of the drug. We are grateful to Dr Giosuè Scognamiglio from the National Cancer Institute of Naples, for performing histopathological experiments. Dr Sabrina Bimonte, Dr Antonio Barbieri, Dr Marco Cascella and Dr Domenica Rea are co-first authors.

\section{Disclosure}

The authors report no conflicts of interest in this work.

\section{References}

1. Molla Hassan AT, Hassan ZM, Moazzeni SM, et al. Naloxone can improve the anti-tumor immunity by reducing the CD4+ CD25+ Foxp3+ regulatory T cells in BALB/c mice. Int Immunopharmacol. 2009;9(12): 1381-1386.

2. Jahangiri S, Abtahi Froushani SM, Delirezh N. Combination immunotherapy with extract of heated 4T1 and naloxone in mouse model of breast cancer. Turk J Med Sci. 2016;46(2):518-523.

3. Motaharinia Y, Rezaee MA, Rashidi A, et al. Induction of protective immunity against brucellosis in mice by vaccination with a combination of naloxone, alum, and heat-killed Brucella melitensis $16 \mathrm{M}$. J Microbiol Immunol Infect. 2012;46(4):253-258. 
4. Ashkenazi A, Dixit VM. Apoptosis control by death and decoy receptors. Curr Opin Cell Biol. 1999;11(2):255-260.

5. Hanahan D, Weinberg RA. The hallmarks of cancer. Cell. 2000;100(1): $57-70$.

6. Hengartner MO. The biochemistry of apoptosis. Nature. 2000;407(6805): 770-776

7. Zagon IS, McLaughlin PJ. Opioids and the apoptotic pathway in human cancer cells. Neuropeptides. 2003;37(2):79-88.

8. Maneckjee R, Minna JD. Opioids induce while nicotine suppresses apoptosis in human lung cancer cells. Cell Growth Differ. 1994;5(10) 1033-1040.

9. Song Y, Shen H, Ding AS, Fan M. [Effects of naloxone on rat cortical neuron apoptosis induced by anoxia]. Zhongguo Wei Zhong Bing Ji Jiu Yi Xue. 2003;15(9):553-556.

10. Childers SR. Opioid receptors: pinning down the opiate targets. Curr Biol. 1997;7(11):R695-R697.

11. Brogan SE, Winter NB. Patient-controlled intrathecal analgesia for the management of breakthrough cancer pain: a retrospective review and commentary. Pain Med. 2011;12(12):1758-1768.

12. Greco MT, Corli O, Montanari M, et al; Writing Protocol Committee; Cancer Pain Outcome Research Study Group (CPOR SG) Investigators. Epidemiology and pattern of care of breakthrough cancer pain in a longitudinal sample of cancer patients: results from the Cancer Pain Outcome Research Study Group. Clin J Pain. 2011;27(1):9-18.

13. Cascella M, Muzio MR, Viscardi D, Cuomo A. Features and role of minimally invasive palliative procedures for pain management in malignant pelvic diseases: a review. Am J Hosp Palliat Care. 2017;34(6): 524-531.

14. Pasternak GW. Pharmacological mechanisms of opioid analgesics. Clin Neuropharmacol. 1993;16(1):1-18.

15. Kieffer BL, Gaveriaux-Ruff C. Exploring the opioid system by gene knockout. Prog Neurobiol. 2002;66(5):285-306.

16. Sueoka N, Sueoka E, Okabe S, Fujiki H. Anti-cancer effects of morphine through inhibition of tumour necrosis factor-alpha release and mRNA expression. Carcinogenesis. 1996;17(11):2337-2341.

17. Hatzoglou A, Bakogeorgou E, Papakonstanti E, Stournaras C, Emmanouel DS, Castanas E. Identification and characterization of opioid and somatostatin binding sites in the opossum kidney (OK) cell line and their effect on growth. $J$ Cell Biochem. 1996;63(4):410-421.

18. Hatzoglou A, Ouafik L, Bakogeorgou E, Thermos K, Castanas E. Morphine cross-reacts with somatostatin receptor SSTR2 in the T47D human breast cancer cell line and decreases cell growth. Cancer Res. 1995;55(23):5632-5636.

19. Maneckjee R, Biswas R, Vonderhaar BK. Binding of opioids to human MCF-7 breast cancer cells and their effects on growth. Cancer Res. 1990; 50(8):2234-2238.

20. Kallergi G, Tsapara A, Kampa M, et al. Distinct signaling pathways regulate differential opioid effects on actin cytoskeleton in malignant MCF7 and nonmalignant MCF12A human breast epithelial cells. Exp Cell Res. 2003;288(1):94-109.

21. Tegeder I, Grosch S, Schmidtko A, et al. G protein-independent G1 cell cycle block and apoptosis with morphine in adenocarcinoma cells: involvement of p53 phosphorylation. Cancer Res. 2003;63(8): 1846-1852.
22. Yeager MP, Colacchio TA. Effect of morphine on growth of metastatic colon cancer in vivo. Arch Surg. 1991;126(4):454-456.

23. Sasamura T, Nakamura S, Iida Y, et al. Morphine analgesia suppresses tumor growth and metastasis in a mouse model of cancer pain produced by orthotopic tumor inoculation. Eur J Pharmacol. 2002;441(3): 185-191.

24. Harimaya Y, Koizumi K, Andoh T, Nojima H, Kuraishi Y, Saiki I. Potential ability of morphine to inhibit the adhesion, invasion and metastasis of metastatic colon 26-L5 carcinoma cells. Cancer Lett. 2002;187(1-2): 121-127.

25. Simon RH, Arbo TE. Morphine increases metastatic tumor growth. Brain Res Bull. 1986;16(3):363-367.

26. Ishikawa M, Tanno K, Kamo A, Takayanagi Y, Sasaki K. Enhancement of tumor growth by morphine and its possible mechanism in mice. Biol Pharm Bull. 1993;16(8):762-766.

27. Bimonte S, Barbieri A, Palma G, Arra C. The role of morphine in animal models of human cancer: does morphine promote or inhibit the tumor growth? Biomed Res Int. 2013;2013:258141.

28. Bimonte S, Barbieri A, Rea D, et al. Morphine promotes tumor angiogenesis and increases breast cancer progression. Biomed Res Int. 2015; 2015:161508

29. Folkman J. Angiogenesis in cancer, vascular, rheumatoid and other disease. Nat Med. 1995;1(1):27-31.

30. Carmeliet P, Jain RK. Angiogenesis in cancer and other diseases. Nature. 2000;407(6801):249-257.

31. Niu DG, Peng F, Zhang W, et al. Morphine promotes cancer stem cell properties, contributing to chemoresistance in breast cancer. Oncotarget. 2015;6(6):3963-3976

32. Kikuchi Y, Kita T, Miyauchi M, Kizawa I, Oomori K, Kato K. Effects of naloxone on human ovarian cancer cell growth in vitro and in vivo. Jpn J Cancer Res. 1987;78(5):519-525.

33. Farooqui M, Geng ZH, Stephenson EJ, Zaveri N, Yee D, Gupta K. Naloxone acts as an antagonist of estrogen receptor activity in MCF-7 cells. Mol Cancer Ther. 2006;5(3):611-620.

34. Gupta K, Kshirsagar S, Chang L, et al. Morphine stimulates angiogenesis by activating proangiogenic and survival-promoting signaling and promotes breast tumor growth. Cancer Res. 2002;62(15):4491-4498.

35. Rea D, Coppola C, Barbieri A, et al. Strain analysis in the assessment of a mouse model of cardiotoxicity due to chemotherapy: sample for Preclinical Research. In Vivo. 2016;30(3):279-290.

36. Bosari S, Lee AK, DeLellis RA, Wiley BD, Heatley GJ, Silverman ML. Microvessel quantitation and prognosis in invasive breast carcinoma. Hum Pathol. 1992;23(7):755-761.

37. Matsuyama K, Chiba Y, Sasaki M, Tanaka H, Muraoka R, Tanigawa N. Tumor angiogenesis as a prognostic marker in operable non-small cell lung cancer. Ann Thorac Surg. 1998;65(5):1405-1409.

38. Avdalyan A, Bobrov I, Klimachev V, Lazarev A. Prognostic value of microvessel density in tumor and peritumoral area as evaluated by CD31 protein expression and argyrophilic nucleolar organizer region count in endothelial cells in uterine leiomyosarcoma. Sarcoma. 2012; 2012:594512.

39. Bimonte S, De Angelis A, Quagliata L, et al. Ofd 1 is required in limb bud patterning and endochondral bone development. Dev Biol. 2011; 349(2):179-191.
OncoTargets and Therapy

\section{Publish your work in this journal}

OncoTargets and Therapy is an international, peer-reviewed, open access journal focusing on the pathological basis of all cancers, potential targets for therapy and treatment protocols employed to improve the management of cancer patients. The journal also focuses on the impact of management programs and new therapeutic agents and protocols on

\section{Dovepress}

patient perspectives such as quality of life, adherence and satisfaction. The manuscript management system is completely online and includes a very quick and fair peer-review system, which is all easy to use. Visit http://www.dovepress.com/testimonials.php to read real quotes from published authors. 